\title{
SPECTROSCOPIC STUDIES IN InGaN QUANTUM WELLS
}

\author{
S. F. Chichibu, ${ }^{* * * *}$ T. Sota ${ }^{* * *}$, K. Wada, ${ }^{* * * *}$ S. P. DenBaars, ${ }^{*}$ S. Nakamura ${ }^{* * * * * *}$ \\ *Materials and ECE Departments, University of California, Santa Barbara, CA 93106 \\ ** Department of EE, Science University of Tokyo, 2641 Yamazaki, Noda, Chiba 278-8510, Japan, \\ chichibu@rs.noda.sut.ac.jp \\ EECE Department, Waseda University, 3-4-1 Ohkubo, Shinjuku, Tokyo 169-8555, Japan \\ ***** Department of Materials Science and Engineering, Massachusetts Institute of Technology, 77 \\ Massachusetts Ave., Cambridge, MA 02139 \\ ****** Department of Research and Development, Nichia Chemical Industries Ltd., 491 Oka, Kaminaka, \\ Anan, Tokushima 774-8601, Japan
}

Cite this article as: MRS Internet J. Nitride Semicond. Res. 4S1, G2.7(1999).

$\underline{\text { Abstract }}$

Fundamental electronic modulations in strained wurtzite III-nitride, in particular $\operatorname{In}_{\mathrm{x}} \mathrm{Ga}_{1-\mathrm{x}} \mathrm{N}$, quantum wells (QWs) were treated to explore the reason why practical InGaN devices emit bright luminescences in spite of the large threading dislocation (TD) density. The emission mechanisms were shown to vary depending on the well thickness L and InN molar fraction $\mathrm{x}$. The electric field across the QW plane, $\mathrm{F}$, which is a sum of the fields due to spontaneous and piezoelectric polarization and the pn junction field, causes the redshift of the ground state resonance energy through the quantum confined Stark effect (QCSE). The absorption spectrum is modulated by QCSE, quantum-confined Franz-Keldysh effect (QCFK), and Franz-Keldysh (FK) effect from the barrires when, for the first approximation, potential drop across the well $\left(\mathrm{F}\right.$ L) exceeds the valence band discontinuity, $\mathrm{E}_{\mathrm{V}}$. Under large $\mathrm{F} \mathrm{L}$, holes are confined in the triangular potential well formed at one side of the well. This produces apparent Stokes-like shift in addition to the in-plane net Stokes shift on the absorption spectrum. The QCFK and FK further modulate the electronic structure of the wells with $\mathrm{L}$ greater than the three dimensional (3D) free exciton (FE) Bohr radius, $a_{B}$. When $F$ L exceeds $E_{C}$, both electron (e) and hole (h) confined levels drop into the triangular potential wells at opposite sides of the wells, which reduces the wavefunction overlap. Doping of Si in the barriers partially screens the F resulting in a smaller Stokes-like shift, shorter recombination decay time, and higher emission efficiency. Finally, the use of InGaN was found to overcome the field-induced oscillator strength lowering due to the spontaneous and piezoelectric polarization. Effective in-plane localization of the QW excitons (confined excitons, or quantized excitons) in quantum disk (Q-disk) size potential minima, which are produced by nonrandom alloy potential fluctuation enhanced by the large bowing parameter and $\mathrm{F}$, produces confined e-h pairs whose wavefunctions are still overlapped when $\mathrm{L}<\mathrm{a}_{\mathrm{B}}$. Their Coulomb interaction is more pronounced for $\mathrm{F} L<\mathrm{E}_{\mathrm{V}}$.

$\underline{\text { Introduction }}$

Major developments of III-nitride semiconductors ${ }^{1,2}$ have led to the commercial production ${ }^{1}$ of blue and green single quantum well (SQW) light-emitting-diodes (LEDs) and to the demonstration of multiple quantum well (MQW) purplish-blue laser diodes (LDs). ${ }^{1-10}$ The growth of nearly TD-free GaN has been realized by the lateral epitaxial overgrowth (LEO) technique, ${ }^{11-16}$ and the device lifetime of the cW MQW LDs has been extended up to 10,000 hours using low TD density GaN on sapphire ${ }^{14}$ and pure GaN substrates $^{15}$ prepared by LEO technique. InGaN alloys are attracting special interest because they are adopted as active regions of ultra-violet (UV), ${ }^{17}$ blue, ${ }^{1}$ green, ${ }^{1}$ and amber $^{18}$ SQW LEDs and all MQW LDs ${ }^{1-}$ 
${ }^{10}$ and they emit bright luminescences despite of the large TD density up to $10^{10} \mathrm{~cm}^{-3}{ }^{19}$ The emission mechanisms in InGaN alloys are not yet fully understood due to complex material physics and engineering, such as large and anisotropic effective masses, ${ }^{20}$ polarization due to the wurtzite crystal lattice, ${ }^{21,22}$ and phase separating nature ${ }^{23,24}$ due to large lattice, thermal, and chemical mismatches.

Several groups have assigned the spontaneous emission from InGaN QWs to the recombination of excitons localized at certain potential minima. ${ }^{1,25-27}$ On the other hand, several groups have discussed the importance of the quantum confined Stark effect $(\mathrm{QCSE})^{28}$ due to the piezoelectric field $\left(\mathrm{F}_{\mathrm{PZ}}\right)$ in strained wurtzite InGaN QWs. ${ }^{2,25,29-31}$ In particular, the blueshift of the electroluminescence (EL) peak in InGaN SQW LEDs ${ }^{1}$ with increasing drive current has been explained ${ }^{1,25}$ by the combined effects of a reduction of QCSE due to Coulomb screening of $\mathrm{F}_{\mathrm{PZ}}{ }^{2,25,29}$ and band-filling of the energy tail states. ${ }^{1,25}$ Moreover, characteristic optical gain mechanisms were reported for InGaN LD wafers ${ }^{25,32-34}$ although gain spectra which can be explained by the well-known e-h plasma (EHP) ${ }^{35}$ lasing model were reported. ${ }^{36-38}$ In order to obtain an insight into what dominates the emission properties of InGaN QWs for further optimization of blue LDs, it is necessary to investigate the effects of effective bandgap inhomogeneity and electric field in the QW separately and consistently.

In this article, several important physics which affect the emission properties of InGaN QWs are discussed. First, the influence of $\mathrm{F}$ was reexamined on $\mathrm{AlGaN} / \mathrm{GaN}$ and $\mathrm{GaN} / \mathrm{InGaN}$ strained QWs to conclude that there exists polarization-induced and junction high electric fields across the strained QWs. Presence of QW excitons is shown for the wells with $\mathrm{L}<\mathrm{a}_{\mathrm{B}}$ even under high $\mathrm{F}$. Next the presence of effective bandgap inhomogeneity, which produces certain quantum disk-size localized potential minima in InGaN, in practical LEDs is shown. Finally the origin of the QW exciton localization was investigated by comparing optical properties of InGaN QWs grown on dislocated GaN-base on sapphire and nearly TD-free GaN overgrown laterally on the $\mathrm{SiO}_{2}$ mask.

\section{Framework}

Optical properties peculiar to wurtzite InGaN and III-nitride materials in comparison to familiar III-V semiconductors such as GaAs or InP known to date are summarized as follows:

(i) Nitrides have an excitonic character in their optical properties. Indeed, dominant resonance structures due to A and B FEs were found in both absorption and photoreflectance spectra of 3D GaN layers, and FE emission has been found even at RT, ${ }^{39,40}$ since the exciton binding energy, $\mathrm{E}_{\mathrm{b}}$, is as large as $26 \mathrm{meV}$ and $\mathrm{a}_{\mathrm{B}}$ is as small as $3.4 \mathrm{~nm}^{20,39-43}$ It is also known that $\mathrm{E}_{\mathrm{b}}$ is increased in $\mathrm{QWs}{ }^{44}$ due to confinement of wavefunctions.

(ii) The wurtzite structure has the highest symmetry compatible with the existence of spontaneous polarization. Moreover, strain-induced piezoelectric tensor of wurtzite has three nonvanishing independent components. In the absence of the external fields, the total macroscopic polarization, $\mathrm{P}$, is the sum of the spontaneous polarization in the equilibrium structure, $\mathrm{P}_{0}$, and of the strain induced piezoelectric polarization, $\mathrm{P}_{\mathrm{PZ}}$.

(iii) InGaN alloys have an immisible gap ${ }^{23,24}$ and they usually show broad luminescence band. ${ }^{1}$ In following arguments follow these information.

\section{$\underline{\text { Polarization in wurtzite lattice }}$}

Since III-nitride epilayers grown on sapphire $(0001)$ or $\mathrm{SiC}(0001)_{\mathrm{Si}}$ substrates are along the c-axis, we shall consider only the polarization along the c-axis, $\mathrm{P}_{3}=\mathrm{P}_{0,3}+\mathrm{P}_{\mathrm{PZ}, 3}$. Bernardini et al. ${ }^{21}$ calculated $\mathrm{P}_{0,3}$ in $\mathrm{AlN}, \mathrm{GaN}$, and $\mathrm{InN}$ as $-0.081,-0.029$, and $-0.032 \mathrm{C} / \mathrm{m}^{2}$, respectively. $\mathrm{P}_{0,3}$ induces the electric field according to $\mathrm{F}_{0,3}=-\mathrm{P}_{0,3} \mathrm{I}_{0}$, and is estimated to be $3.4 \mathrm{MV} / \mathrm{cm}$ for GaN, which is nearly 50 times the ionization field, $\mathrm{F}_{\mathrm{i}}$, of FEs in $3 \mathrm{D} \mathrm{GaN}\left(7.610^{4} \mathrm{~V} / \mathrm{cm}\right){ }^{39}$ From the fact that FE 
emissions can be observed from $3 \mathrm{D}$ GaN even at $\mathrm{RT},{ }^{39} \mathrm{~F}_{0,3}$ should be smaller than $\mathrm{F}_{\mathrm{i}}$. This may be due to internal screening of the polarization since the layer is usually too thick and any kinds of internal charges contribute to screening. An expression for $\mathrm{P}_{\mathrm{PZ}, 3}$ under the biaxial strain $(a$ $\left.a_{0}\right) / a_{0}={ }_{\mathrm{xx}}={ }_{\mathrm{yy}}=-\left(C_{33} / 2 C_{31}\right)_{\mathrm{zz}}$ is given by $\mathrm{P}_{\mathrm{PZ}, 3}=2\left(\mathrm{e}_{31}-\mathrm{e}_{33} \mathrm{C}_{31} / \mathrm{C}_{33}\right)_{\mathrm{xx}}$, where $a$ is the lattice constant, $a_{0}$ is that of strain-free material, $C_{\mathrm{ij}}$ are the elastic stiffness constants, and $\mathrm{e}_{\mathrm{ij}}$ are the piezoelectric constants. Bernardini et al..$^{21}$ reported the following values in units of $\mathrm{C} / \mathrm{m}^{2}: \mathrm{e}_{33}=1.46$ and $\mathrm{e}_{31}=-0.60$ for AIN; $\mathrm{e}_{33}=0.73$ and $\mathrm{e}_{31}=-0.49$ for $\mathrm{GaN} ; \mathrm{e}_{33}=0.97$ and $\mathrm{e}_{31}=-0.57$ for InN. For in-plane compressive strains usually found in InGaN, the direction of $\mathrm{F}_{\mathrm{Pz}}$ is from $\mathrm{Ga}$ face to $\mathrm{N}$ face (surface to substrate) according to Hellman ${ }^{22}$ if we consider the Ga surface growth $(+\mathrm{C})$. The direction of $\mathrm{F}_{\mathrm{PZ}, 3}$ is opposite to $\mathrm{F}_{0,3}$ and the pn junction field $\mathrm{F}_{\mathrm{pn}}$. This means that total electric field $\mathrm{F}$ exists in the QW regions of practical devices is a sum of polarization-induced fields and the pn junction field, $\mathrm{F}_{3}=\mathrm{F}_{0,3}+\mathrm{F}_{\mathrm{pn}}-\mathrm{F}_{\mathrm{PZ}, 3}$. Details of this will be discussed elsewhere, and we simply consider the effect of $\mathrm{F}$ on the band structures of strained QWs in this article.

\section{Schematic band diagrams of InGaN QWs under an electric field}

From the framework (i) and (ii), physical scenarios of the optical transitions in InGaN QWs are drawn as follows. Since the critical thickness of $\operatorname{In}_{x} \mathrm{Ga}_{1-\mathrm{x}} \mathrm{N}(0<\mathrm{x}<0.15)$ is reported to be greater than 40 $\mathrm{nm},{ }^{2,29}$ coherent growth of $\mathrm{InGaN}$ is assumed. This strain causes $\mathrm{F}_{\mathrm{PZ}}$ but excitons should also be significant. Therefore the problem treated here is the behavior of confined energy levels in QWs under $\mathrm{F}$, as discussed for GaAs/AlGaAs QWs in the 1980's. ${ }^{28,44,45}$ In QWs, FE absorption is observed even at RT under high F across the $\mathrm{QW}^{28,44}$ due to quantum confinement of the wavefunctions which enhances the Coulomb interaction between the e-h pair to increase $\mathrm{E}_{\mathrm{b}}{ }^{44}$ Miller et $a{ }^{28}{ }^{28}$ have observed an excitonic absorption in GaAs QWs, which was redshifted by 2.5 times the zero-field $\mathrm{E}_{\mathrm{b}}$ for $\mathrm{F}=10^{5} \mathrm{~V} / \mathrm{cm}$ (50 times the $\mathrm{F}_{\mathrm{i}}$ of 3D excitons). They have explained the redshift in terms of field modulation of quantized energy levels (QCSE). ${ }^{28}$ We estimate ${ }^{46} \mathrm{E}_{\mathrm{b}}$ in $\mathrm{GaN} / \mathrm{Al}_{0.1} \mathrm{Ga}_{0.9} \mathrm{~N} \mathrm{QWs}$ under $\mathrm{F}=0$ as a function of $\mathrm{L}$ according to Bastard $e t$ $a l .{ }^{44}$ introducing finite barrier height. The obtained $\mathrm{E}_{\mathrm{b}}$ value for $\mathrm{L}=3 \mathrm{~nm}$ is $47 \mathrm{meV}$ and $\mathrm{F}_{\mathrm{i}}$ is estimated to be

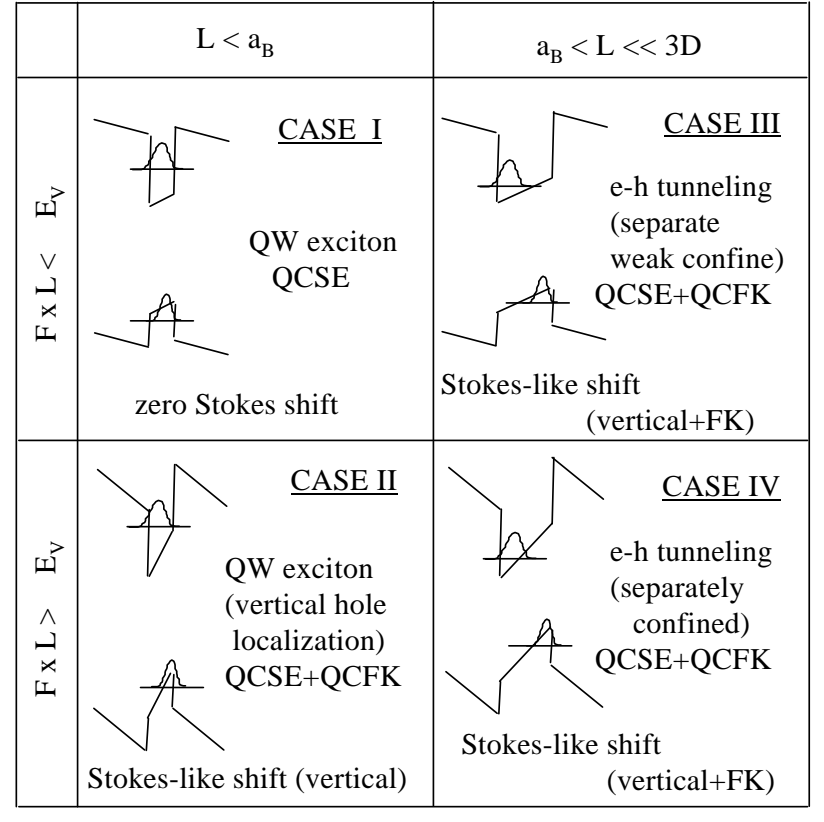

Fig.1 Schematic band diagrams of GaN/InGaN QWs under the electric field $\mathrm{F}$. Each case represents the restrictions determined among $\mathrm{F}, \mathrm{L}, \mathrm{E}_{\mathrm{V}}$, and $\mathrm{a}_{\mathrm{B}}$.
$6.010^{5} \mathrm{~V} / \mathrm{cm}$ taking into account the shrinkage of e-h distance in z-direction down to $0.78 \mathrm{~nm}$. $\mathrm{E}_{\mathrm{b}}$ is $37 \mathrm{meV}$ for $\mathrm{L}=6 \mathrm{~nm}$.

Taking the small fraction (1/4) of $\mathrm{E}_{\mathrm{V}}$ against the conduction band discontinuity $\mathrm{E}_{\mathrm{C}}$ into account, ${ }^{47}$ schematic band diagrams of InGaN / GaN QWs are drawn in Fig. 1 for several cases; i.e. restrictions among FxL, $\mathrm{E}_{\mathrm{V}}$, and $\mathrm{a}_{\mathrm{B}}$. Since the restriction FxL> $\mathrm{E}_{\mathrm{V}}$ breaks before breaking FxL> $\mathrm{E}_{\mathrm{C}}$ with increasing $\mathrm{F}$ or $\mathrm{L}$, restrictions between $\mathrm{FxL}$ and $\mathrm{E}_{\mathrm{V}}$ and between $L$ and $a_{B}$ (quantum size effect) only are drawn in Fig.1. Note that in-plane (lateral) bandgap inhomogeneity is omitted.

In CASE I, both electron and hole wavefunctions are confined in the well and have unique quantized energy levels where zero Stokes-like shift is expected though the resonance energy slightly shifts to lower energy due to QCSE. In CASE II, at least the hole wavefunction drops into the triangular shape 
potential well at one side of the well, and continuum states are formed at the rest of the potential slope inside the QW region. In addition the penetration of the barrier continuum wavefunction cannot be neglected. Therefore vertical component Stokes-like shift is produced. For the extreme situation of CASE II (pronounced CASE II), both the e-h wavefunctions drop into the triangular potential wells formed at opposite sides of the well resulting in z-directional separation. In CASE III and IV, the absorption tail would be modulated due primarily to $\mathrm{QCSE}^{28}$ and QCFK. $^{45}$

\section{Optical properties as a function of QW thickness}

Low excitation PLE and PL spectra at RT of $\operatorname{~In}_{0.1} \mathrm{Ga}_{0.9} \mathrm{~N} / \mathrm{GaN}$ MQWs with various $\mathrm{L}$ are shown in Fig. 2. The PL spectra exhibited a broad luminescence peak due to InGaN QWs, whose full width at half maximum (FWHM) was nearly $120 \mathrm{meV}$. The PL peak showed a redshift by $360 \mathrm{meV}$ with increasing L from 1.2 to $6.2 \mathrm{~nm}$, and the intensity decreased for $\mathrm{L}>3.6 \mathrm{~nm}\left(\mathrm{~L}>\mathrm{a}_{\mathrm{B}}\right)$. The PLE spectra exhibited broadened absorption tail except for the $\mathrm{L}=1.2$ $\mathrm{nm}$ case. The broadening was pronounced for wells with $\mathrm{L}>\mathrm{a}_{\mathrm{B}}$. These results agree with the scenario that the QW configuration changes from CASE I, II, to IV due to increasing $\mathrm{L}$ assuming constant $\mathrm{x}$ and $\mathrm{F}_{\mathrm{PZ}}$. The apparent bandgap energy determined as the energy where the PLE signal intensity drops to half the maximum, PL peak energies, and Stokes-like shifts are plotted as a function of L in Fig. 3. As expected, the apparent Stokes-like shift increased from nearly $50 \mathrm{meV}$ to $220 \mathrm{meV}$. Since in CASE I, zero Stokes-shift is expected if the well had a homogeneous bandgap energy, the observed Stokes shift for CASE I $\left(L<a_{B}\right)$ directly shows the presence of in-plane net Stokes shift due to localized energy states in the QW. Similar results were obtained at $4 \mathrm{~K}$ where the Stokes-shift was nearly $100 \mathrm{meV}(\mathrm{L}<2.5 \mathrm{~nm})$. The observed blueshift of the high excitation PL peak indicates presence of high $\mathrm{F}$ across the wells.

In order to estimate $\mathrm{F}$, confined energy levels and wavefunctions in $\operatorname{In}_{0.1} \mathrm{Ga}_{0.9} \mathrm{~N}$ QWs are calculated as functions of $\mathrm{F}, \mathrm{L}$, and $\mathrm{n}$ in the barrier by variational method neglecting $\mathrm{E}_{\mathrm{b}}$ within the Hartree approximation by solving the Schrödinger equation and Poisson equation simultaneously and selfconsistently. We did not fit the data but simply calculated and compared the relation between the low excitation PL peak energy and $\mathrm{L}(\mathrm{L}<3.6 \mathrm{~nm})$ in Fig. 3. As a result, the zero-field bandgap of the $3 \mathrm{D}$ InGaN well is obtained to be $2.92 \mathrm{eV}$ and $\mathrm{E}_{\mathrm{C}}$ and $\mathrm{E}_{\mathrm{V}}$ are estimated to be about 400 and $100 \mathrm{meV}$, respectively. $F$ is estimated to be nearly $3.510^{5} \mathrm{~V} / \mathrm{cm}$ which gives Stark shift of nearly $45 \mathrm{meV}$ in the 3-nm-thick QW. Examples of the calculated quantized energy levels and e-h wavefunctions for InGaN under $\mathrm{F}=400$

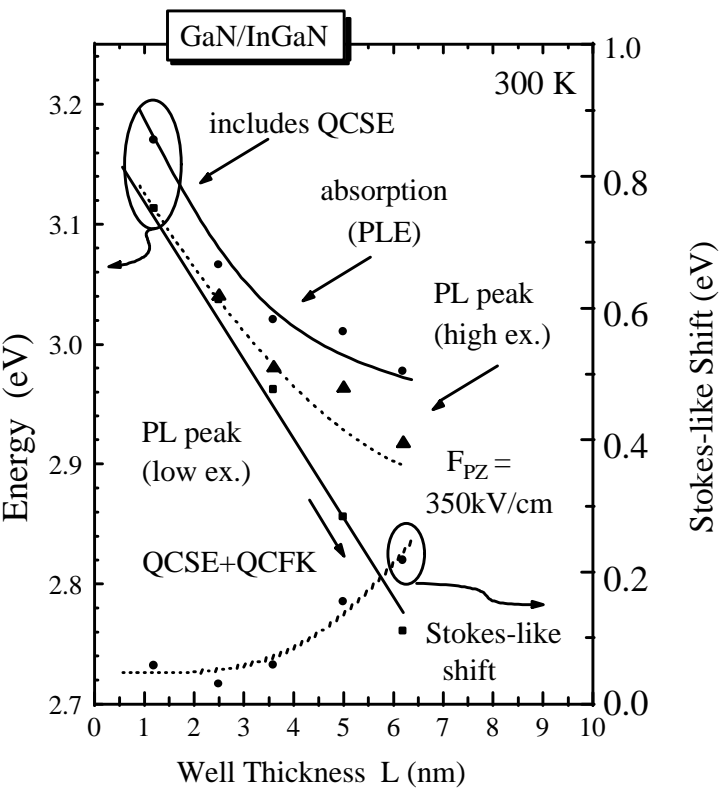

Fig.3 High and low excitation PL peak energies, apparent bandgap energy estimated from PLE spectra, and apparent Stokes-like shift of $\mathrm{In}_{0.1} \mathrm{Ga}_{0.9} \mathrm{~N}$ wells at RT as a function of $\mathrm{L}$. 
$\mathrm{kV} / \mathrm{cm}$ are shown in Fig. 4. Under $\mathrm{F}=3.510^{5} \mathrm{~V} / \mathrm{cm}, \mathrm{F} \mathrm{L}$ exceeds $\mathrm{E}_{\mathrm{V}}$ for $\mathrm{L}>3.4 \mathrm{~nm}$. The hole confined level would already be formed in the triangular potential (CASE II) between 2.5 and 3.6 $\mathrm{nm}$. Beyond this, the system belongs to CASE IV where the e-h are confined in opposite sides of the well, as shown in Fig. 4. This may explain the extremely long decay time in terms of reduction of the oscillator strength for large $\mathrm{L}$ at low temperature where nonradiative recombination is suppressed. At $4 \mathrm{~K}$, was nearly $35 \mathrm{~ns}$ for $\mathrm{L}=5 \mathrm{~nm}\left(>\mathrm{a}_{\mathrm{B}}\right)$. This may cause serious degradation of the
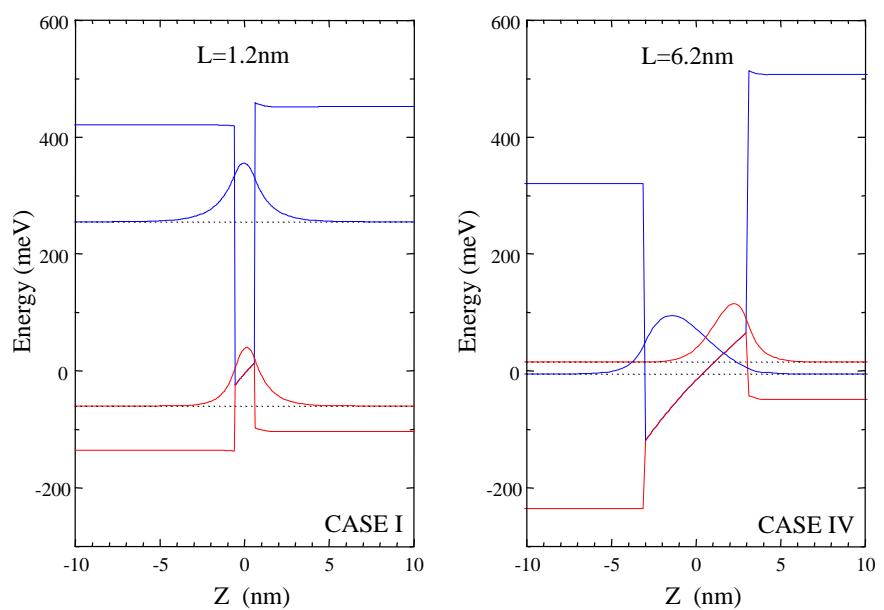

Fig.4 Quantized energy levels and wavefunctions of e-h pair in $\mathrm{In}_{0.1} \mathrm{Ga}_{0.9} \mathrm{~N} \mathrm{SQW}$ under the condition of $\mathrm{F}=400 \mathrm{kV} / \mathrm{cm}$. emission intensity. Relatively shorter (0.97-4 ns) for $\mathrm{L}<2.5 \mathrm{~nm}$ at $4 \mathrm{~K}$ indicates that the overlap of the e-h wavefunction is still large because $\mathrm{L}$ is

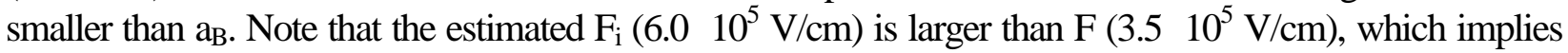
that Coulomb interaction between the e-h pair still remains. This kind of particles can be regarded as QW excitons.

\section{Optical properties as a function of InN molar fraction X}

Next sample series have a 3-nm-thick InGaN SQW with various x, which correspond to CASE I, II, and pronounced CASE II. Note that change in $x$ changes in $E_{C}, E_{V}$, and $F_{\mathrm{PZ}}$ simultaneously. The PLE spectra broadened and the PL peak energy showed pronounced redshift with increasing $x$, as shown in Fig. 5. The QW ( $\mathrm{x}=0.03)$ exhibited a sharp onset of the PLE spectra at $3.3 \mathrm{eV}$, as is the case with $\mathrm{L}=1.2 \mathrm{~nm}$ in Fig. 2. If we assume a linear relation between $\mathrm{F}_{\mathrm{PZ}}$ and $\mathrm{x}, \mathrm{F}_{\mathrm{PZ}}$ is estimated to be nearly $1.110^{5} \mathrm{~V} / \mathrm{cm}$. The PLE spectra were taken at $10 \mathrm{~K}$, and the sample is considered to belong to CASE I, as shown in Fig. 6. The appearance of the Stokes shift in the CASE I sample again indicates the presence of localized energy states. With increasing x, first the hole confined level drops into the triangular potential, as shown in Fig. 6 (400 $\mathrm{kV} / \mathrm{cm}$ ), and that of electron will also drop into the triangular potential at opposite side for higher $\mathrm{x}$ (pronounced CASE II). This scenario explain the broadness of the PLE spectra with increasing $x$. In

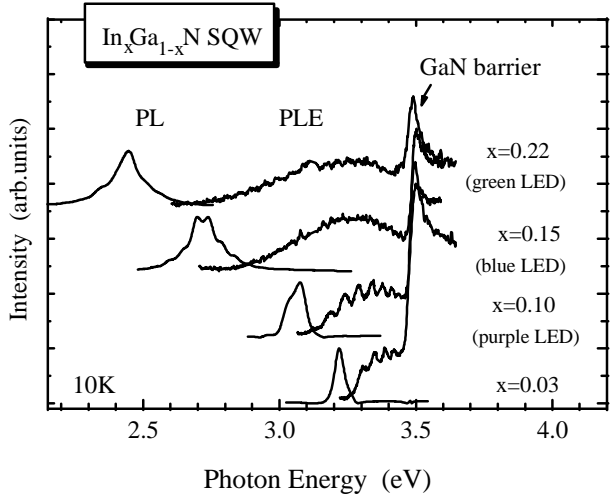

Fig.5 Low excitation PL and PLE spectra at $10 \mathrm{~K}$ of 3-nm-thick $\operatorname{In}_{\mathrm{x}} \mathrm{Ga}_{1-\mathrm{x}} \mathrm{N} / \mathrm{GaN}$ :Si SQW structures with different $\mathrm{InN}$ molar fraction, $\mathrm{x}$. The $\mathrm{x}$ values are estimated assuming coherent growth.
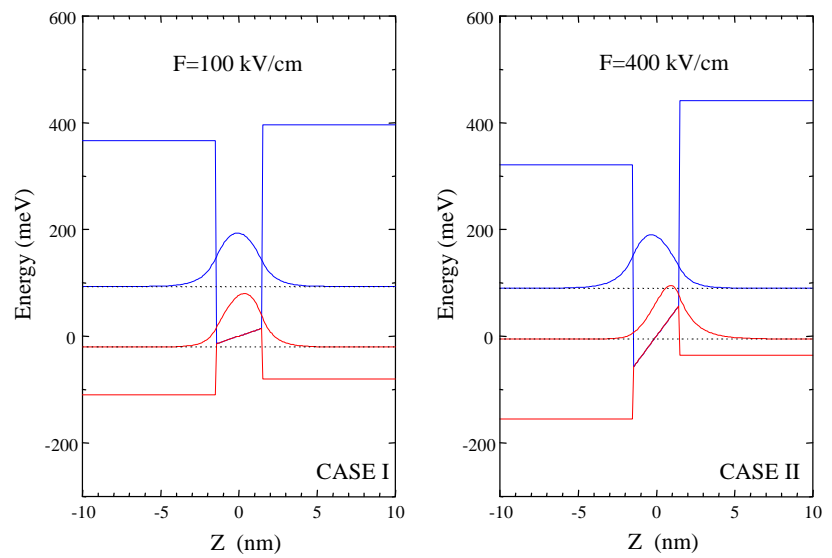

Fig.6 Quantized energy levels and wavefunctions of e-h pair in 3-nm-thick InGaN SQW under the condition of $\mathrm{F}=100 \mathrm{kV} / \mathrm{cm}(\mathrm{x}=0.03)$ and $400 \mathrm{kV} / \mathrm{cm}(\mathrm{x}=0.1)$. 
addition, the spatial separation of the e-h pair normal to the QW plane may reduce the wavefunction overlap and increase the emission decay time with increasing $\mathrm{x}$. However, as shown in Fig.6, the overlap of e-h wavefunction is still large.

Both the Stokes-like shift and the decay time had a critical $x^{25}$ of nearly 0.1 as shown in Fig. 7. This composition is considered to correspond to the point that the band diagram changes from CASE I to CASE II or pronounced CASE II where the absorption due to continuum states from barriers becomes remarkable. On the other hand, the degree of effective bandgap inhomogeneity suddenly increases by alloying In then increase monotonically with increasing $\mathrm{x}$, judging from the values of PL FWHM, as shown in Fig. 7.

\section{Coulomb screening effects by Si-doping of GaN barriers}

One of the effective methods to screen polarizationinduced $\mathrm{F}$ is by doping the wells or barriers. If the injected or

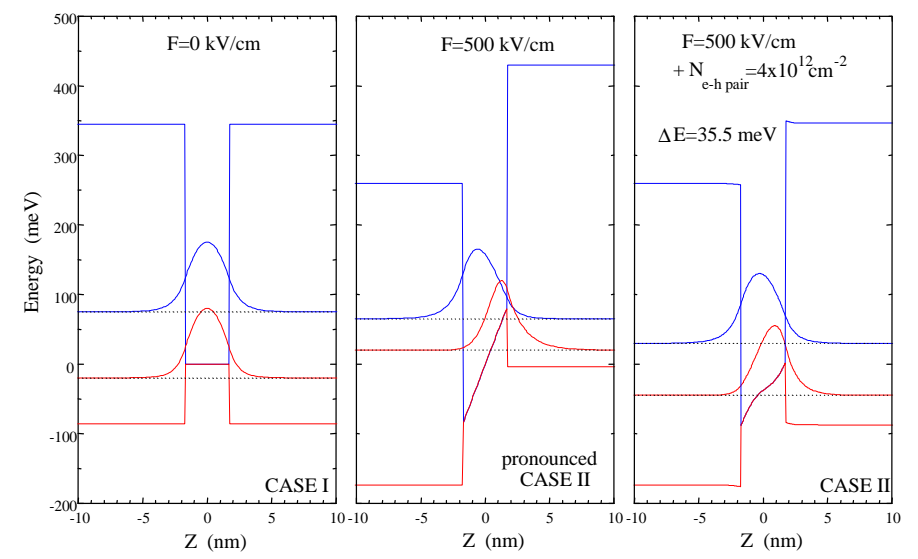

Fig.8 Quantized energy levels and wavefunctions of e-h pair in 3-nm-thick InGaN SQW under the condition of $\mathrm{F}=0 \mathrm{kV} / \mathrm{cm}$, $\mathrm{F}=500 \mathrm{kV} / \mathrm{cm}$, and $\mathrm{F}=500 \mathrm{kV} / \mathrm{cm}$ and $\mathrm{N}_{\mathrm{e}-\mathrm{h} \text { pair }}=410^{12} \mathrm{~cm}^{-2}$.

different Si-doping concentrations in the $\mathrm{GaN}$ barriers were examined. $\mathrm{F}_{\mathrm{PZ}}$ in the undoped $\mathrm{MQW}$ is estimated to be 5-6 $10^{5} \mathrm{~V} / \mathrm{cm}$. The PL peak shifted to higher energy and the absorption tail in the PLE spectrum decreased by doping Si up to $10^{19} \mathrm{~cm}^{-3}$, as shown in Fig. 9. The apparent resonance energy shifted to higher energy by $50 \mathrm{meV}$, which nearly agrees with Fig.8, and the apparent Stokes-like shift decreased from $220 \mathrm{meV}$ to $120 \mathrm{meV}$. At the same time, the emission decay time decreased from $14 \mathrm{~ns}$ to $850 \mathrm{ps}$ with increasing Sidoping. These results indicate that $\mathrm{F}_{\mathrm{PZ}}$ was effectively screened, and the overlap of the e-h wavefunction was recovered. Note that screening of $\mathrm{F}_{\mathrm{PZ}}$ reduces the slope of the conduction and valence bands within the QW to

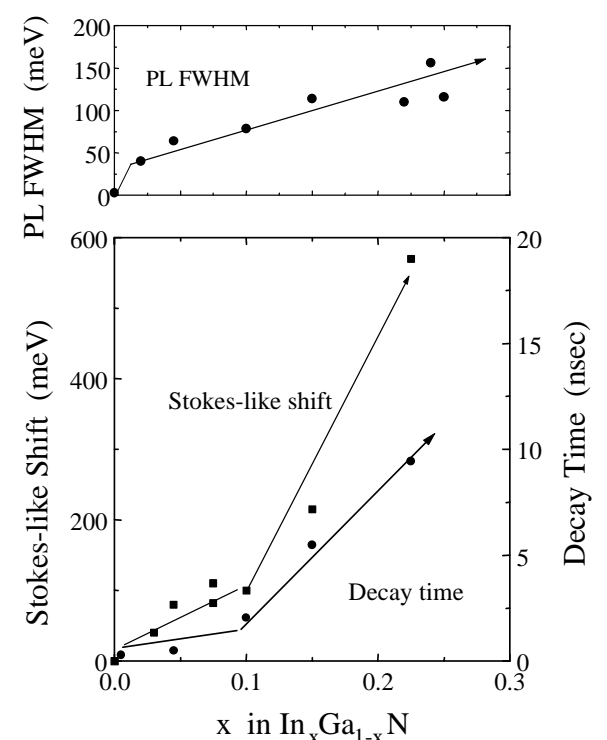

Fig.7 PL FWHM, apparent Stokes-like shift, and TR-PL decay time of 3-nm-thick $\operatorname{In}_{\mathrm{x}} \mathrm{Ga}_{1-\mathrm{x}} \mathrm{N}$ QWs as a function of $\mathrm{x}$.

doped charge density is enough to screen $\mathrm{F}_{\mathrm{PZ}}$, the pronounced CASE II QWs may recover wavefunction overlap. ${ }^{25}$ Quantized energy levels and wavefunctions of a 3-nmthick $\mathrm{In}_{0.13} \mathrm{Ga}_{0.87} \mathrm{~N}$ SQWs for $\mathrm{F}=0, \mathrm{~F}=500$ $\mathrm{kV} / \mathrm{cm}$, and $\mathrm{F}=500 \mathrm{kV} / \mathrm{cm}$ with injected e$\mathrm{h}$ pair density of $410^{12} \mathrm{~cm}^{-2}$ are shown in Fig. 8. As shown, the wavefunction overlap and the transition energy between the energy levels were recovered by the $\mathrm{Si}$ doping. To confirm this experimentally, 3nm-thick $\operatorname{In}_{0.13} \mathrm{Ga}_{0.87} \mathrm{~N} / \mathrm{GaN}$ MQWs with

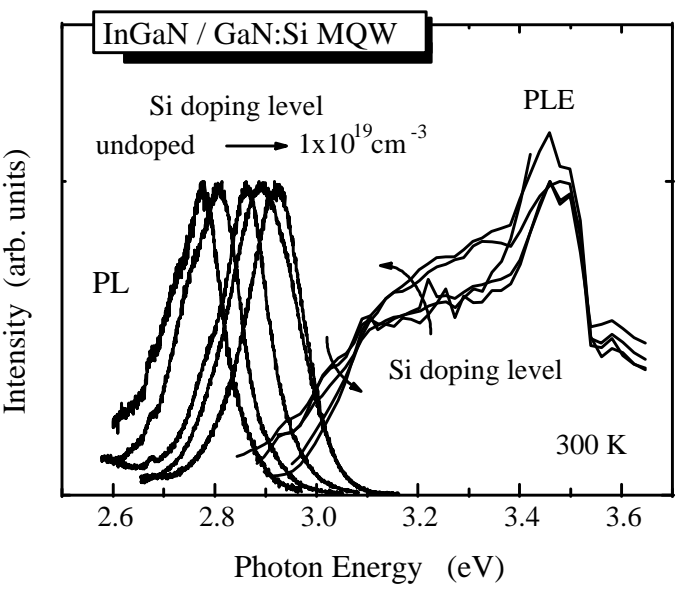

Fig.9 Low-excitation PL and PLE spectra at $300 \mathrm{~K}$ of $\mathrm{In}_{0.13} \mathrm{Ga}_{0.87} \mathrm{~N} / \mathrm{GaN} \mathrm{MQWs}$ for different Si-doping concentrations (n). PLE edge was sharpened and the PL peak blueshifted with increasing $n$. 
result in sharp onset of the absorption tail. This reduces the "vertical" component of the apparent Stokes-like shift. Of course, increased electron density due to the modulation doping may improve the radiative recombination rate, and the electrons will fill the energy tail states at the same time. The sample with the highest doping level showed the shortest $=850 \mathrm{ps}$ and the brightest emission. This value seems to be close to the intrinsic radiative recombination lifetime. The longer usually observed in the practical LEDs will be discussed later.

Why InGaN emits efficient luminescences / In-plane localization of QW excitons

Blue and green InGaN SQW LEDs show blueshift of the EL peak energy with increasing driving current. ${ }^{1,25,48}$ This has been explained by combined effects of Coulomb screening of $\mathrm{F}_{\mathrm{PZ}}$ and band filling of the localized energy states by QW excitons. ${ }^{25}$ Really recently, Mukai et al. ${ }^{49}$ reported that current and temperature dependences of the EL peak energy of 5.5-nm-thick $\operatorname{In}_{x} \mathrm{Ga}_{1-\mathrm{x}} \mathrm{N}$ SQW LEDs change drastically at a critical emission peak wavelength of $375 \mathrm{~nm}$. When $\mathrm{x}$ is very small, LEDs do not show any blueshifts but show temperature dependence. Conversely, when $\mathrm{x}$ is larger than corresponding emission peak of $375 \mathrm{~nm}$, the LEDs show nearly temperature-independent but current density-dependent EL peak energy. Moreover, the output power of UV LEDs increase with increasing wavelength in UV region longer than 370nm where the self-absorption due to GaN base layer is already negligible. These results indicate that the emission mechanisms change with $\mathrm{x}$, and those of GaN QW and InGaN QW are totally different.

Another supporting evidence of the importance of exciton localization in InGaN is shown in Fig. 10. Figure 10 shows the optical transmittance at $10 \mathrm{~K}$ and RT and high excitation PL spectra at RT of a 5-nm-thick $\mathrm{GaN} / \mathrm{Al}_{0.15} \mathrm{Ga}_{0.85} \mathrm{~N}$ double-hetero (DH) structure grown on thick $\mathrm{Al}_{0.3} \mathrm{Ga}_{0.7} \mathrm{~N}$ base layer and those of 5.5-nm-thick $\mathrm{Al}_{0.15} \mathrm{Ga}_{0.85} \mathrm{~N} / \mathrm{InGaN} / \mathrm{Al}_{0.1} \mathrm{Ga}_{0.9} \mathrm{~N} \mathrm{DH}$ structure (SQW UVLED $)^{49}$ grown on thick GaN base. Since the former sample was grown on thick $\mathrm{Al}_{0.3} \mathrm{Ga}_{0.7} \mathrm{~N}$ to observe QW absorption spectrum, both GaN/AlGaN/AlGaN and InGaN/AlGaN/GaN QWs suffer from compressive biaxial strain. Then the $\mathrm{F}_{\mathrm{PZ}}$ is opposite to the pn junction field. Against $\mathrm{F}_{\mathrm{PZ}}$, the GaN/AlGaN SQW exhibits an excitonic absorption peak up to RT, as predicted form the increase of $\mathrm{E}_{\mathrm{b}}$ in QWs. ${ }^{25,28,46,50}$ Therefore InGaN SQW would also show the excitonic character. Since the PL peak energy of InGaN/AlGaN SQW is higher than that of GaN/AlGaN SQW, the QW resonance energy of GaN/AlGaN should be smaller than that of InGaN/AlGaN structure, which means that QCSE due to $\mathrm{F}_{\mathrm{PZ}}$ dominates the optical transitions in the binary GaN wells. Accordingly, the PL intensity of GaN/AlGaN SQW was far lower than that of $\mathrm{InGaN} / \mathrm{AlGaN}$, although the self-absorption due to the $\mathrm{GaN}$ base is remarkable for the particular UV-LED structure. Note that the PL peak energy agrees with the excitonic absorption peak at RT and excitons are delocalized for the GaN/AlGaN SQW, which is different from the results obtained from $\mathrm{InGaN}$ QWs.

Typical wide-area and spotexcitation CL spectra at $10 \mathrm{~K}$ of a 3nm-thich $\operatorname{In}_{0.1} \mathrm{Ga}_{0.9} \mathrm{~N}$ SQW are shown

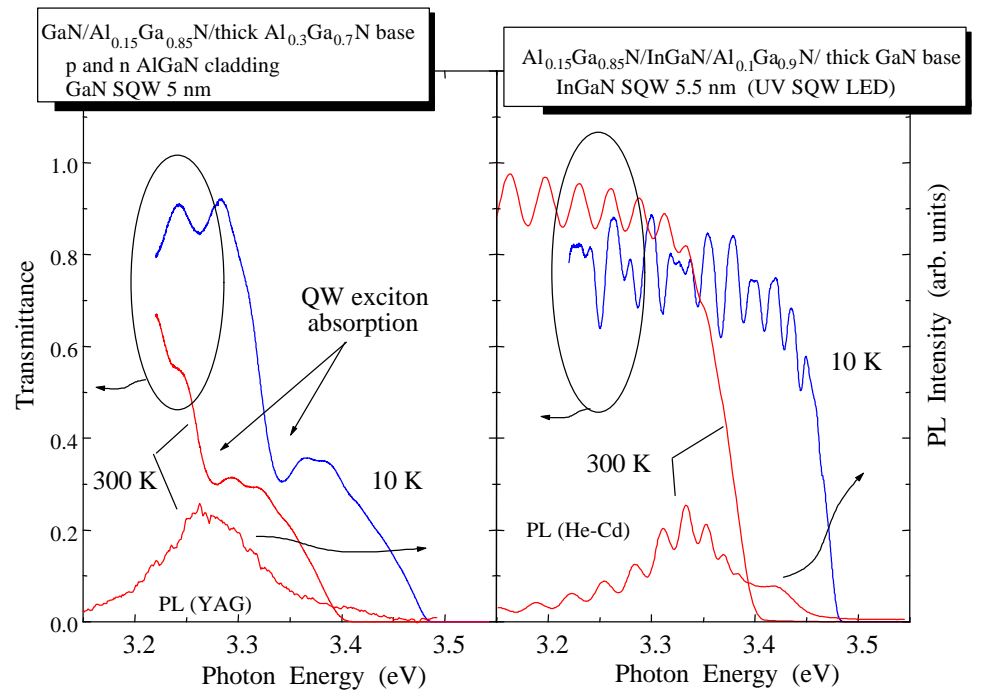

Fig. 10 Optical transmittance and high excitation PL spectra at $10 \mathrm{~K}$ and RT of a 5-nm-thick GaN / $\mathrm{Al}_{0.15} \mathrm{Ga}_{0.85} \mathrm{~N}$ DH structure grown on thick $\mathrm{Al}_{0.3} \mathrm{Ga}_{0.7} \mathrm{~N}$ base layer and those of $5.5-\mathrm{nm}$-thick InGaN / $\mathrm{Al}_{0.1} \mathrm{Ga}_{0.9} \mathrm{~N}$ DH structure (SQW UV-LED) ${ }^{49}$ grown on thick GaN base. 

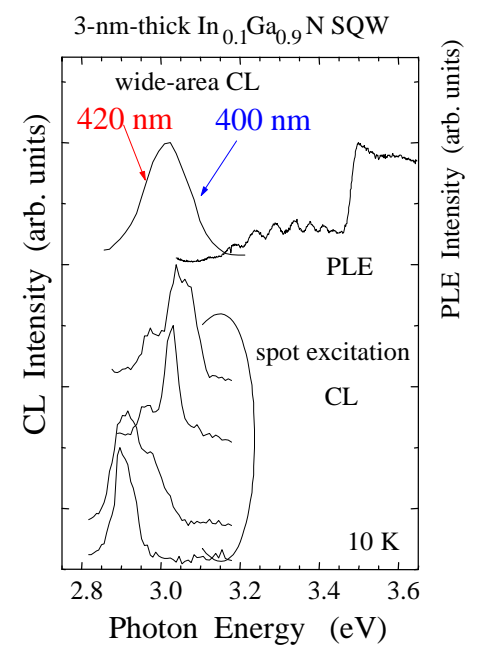
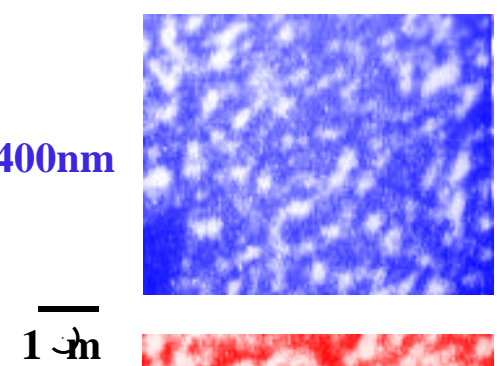

420nm

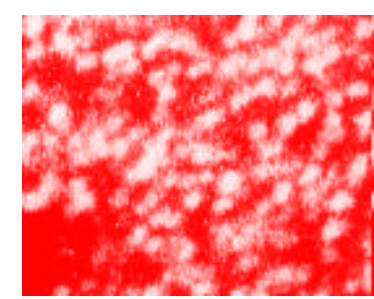

Fig.11 Wide-area (10 m $10 \mathrm{~m})$ scanning and spot excitation CL spectra of 3-nmthick $\operatorname{In}_{0.1} \mathrm{Ga}_{0.9} \mathrm{~N}$ SQW capped by a 6-nm-thick GaN. The broad CL peak (FWHM=100 meV) consists of several sharp emission peaks (FWHM=20 meV) having different peak energies. Monochromatic CL images taken at 400 and $420 \mathrm{~nm}$ showed primarily the complimentary relation. The resolution of the CL mapping is limited by the diffusion length, which was nearly $60 \mathrm{~nm}$ in lateral direction.

in Fig. 11. Although the effect of the multiple interference fringes on the CL spectra is not negligible, wide area $(10 \mathrm{~m} 10$

m) broad CL band (FWHM nearly $100 \mathrm{meV}$ ) consists of many sharp peaks (FWHM less than $20 \mathrm{meV})^{51}$ at $10 \mathrm{~K}$. This clearly shows that the broad CL band consists of sharper emission peaks having various peak energies. Therefore, there exist several structures composed of an InN-rich part surrounded by a GaN-rich part in each spot area. This structure may be due to mesoscopic compositional undulation and it can act as quantum-disks (Qdisks), ${ }^{52}$ dots, or segmented QWs having compositional and/or size inhomogeneity. Monochromatic scanning CLimages of the same GaN-capped $\operatorname{In}_{0.1} \mathrm{Ga}_{0.9} \mathrm{~N}$ SQW taken at wavelengths of $400 \mathrm{~nm}$ and $420 \mathrm{~nm}$ are also shown in Fig. 11. A careful comparison between the two images using a triangular-shaped dark marker on the bottom-left corner indicated following results; (a) each bright (white in the figure) area consists of emissions from real spaces of about 60-400 nm in lateral size, (b) some dark areas in one figure correspond complementary to bright ones in the other figure, and (c) some areas exhibit both 400 and $420 \mathrm{~nm}$ CL emissions. These results can also be explained by the existence of compositional undulation whose lateral interval is smaller than $60 \mathrm{~nm}$, which value is the spatial resolution of the system (diffusion length). Supporting evidences of the short diffusion length in InGaN QWs were reported by Rosner et al. ${ }^{53,54}$ They showed less pronounced CL contrast in InGaN SQW compared to GaN. ${ }^{54}$ Sato et al. ${ }^{55}$ estimated the PL intensity as a function of TD density and also supported the short diffusion length model in InGaN QWs. ${ }^{51}$ The result (c) indicates that the real area that emits CL is far smaller than the diffusion length $(60 \mathrm{~nm})$. Kisielowski et al. ${ }^{56}$ and Ponce et al..$^{57}$ estimated the structural size of InN-rich clusters to be less than $10 \mathrm{~nm}$ and $20 \mathrm{~nm}$, respectively. Such CL nanostructure was also found for compositions as low as $\mathrm{x}=0.03$. This means that large FWHM of the PL peak and broadness of the PLE signal edge for the CASE I QWs represent the in-plane effective emission bandgap inhomogeneity. Note that e-h wavefunctions in the Q-disks are confined with respect to the $z$-direction, and Q-disks or Qdots can improve the emission efficiency of QW excitons due to the lateral confinement in limited spaces, that can reduce nonradiative pathways. This is the reason why InGaN exhibits bright spontaneous emissions. Naturally, it overcomes disadvantages of using wurtzite materials due to the polarization-induced electric fields. The e-h wavefunctions are still overlapped even in the pronounced CASE II. The emission lifetime is affected by both the e-h pair separation due to $\mathrm{F}_{\mathrm{PZ}}$ and in-plane localization for CASE II and pronounced CASE II. In Q-disks, the spontaneous emission lifetime becomes long since the emission is prohibited when the wave vector of exciton center-of-mass motion is above the critical energy. ${ }^{52}$

\section{Origin of exciton localization}

One of the possible origins of the in-plane bandgap inhomogeneity is an inhomogeneous 


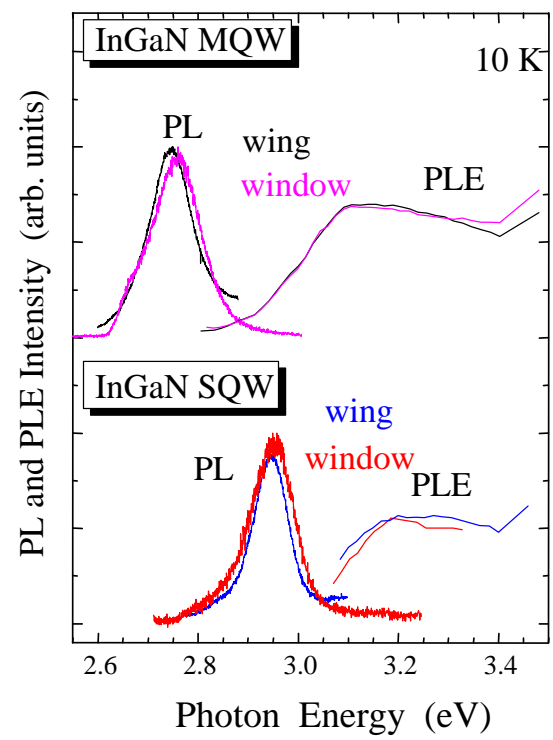

Fig. $12 \mathrm{PL}$ and PLE spectra at $10 \mathrm{~K}$ obtained from InGaN SQW and MQW structures grown on LEO window and LEO wing regions.

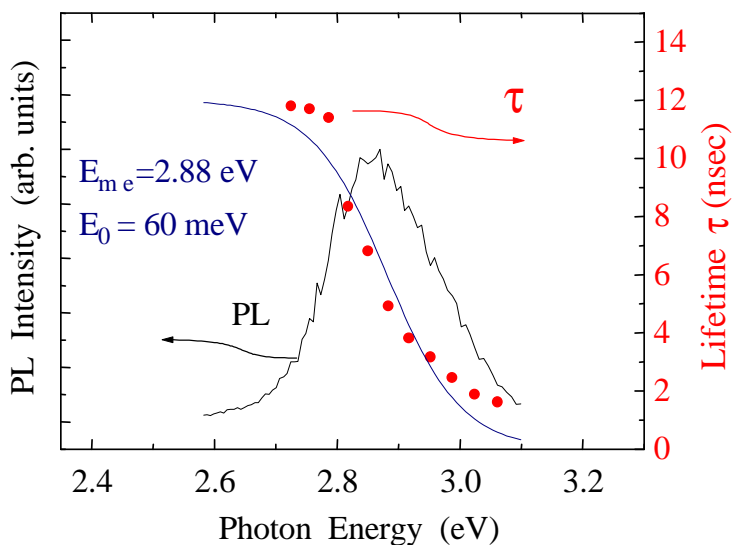

Fig. 13 Time-integrated PL spectra and the decay time as a function of emission energy at RT of InGaN MQW grown on the LEO wing.

distribution of $\mathrm{F}_{\mathrm{PZ}}$ due to strain fluctuation. If we attribute the in-plane net Stokes shift to this, the potential fluctuation can be leveled by filling carriers to screen $\mathrm{F}_{\mathrm{PZ}}$. However, the FWHM of PL or EL in InGaN QWs does not change or even increase

with increasing excitation level. Therefore, an intrinsic compositional inhomogeneity is the most probable. Keller et al. ${ }^{58}$ found a spiral growth of InGaN initiated by the mixed character TDs. If such a growth mode accumulates In to the growth step edge, compositional inhomogeneity would be produced. To investigate this, optical properties of InGaN QWs were investigated as a function of TD density ${ }^{59}$ using LEO technique. A series of InGaN QWs were grown on dislocated $\mathrm{GaN}$ grown from the $\mathrm{SiO}_{2}$ mask opening (window) and nearly TD-free GaN laterally overgrown on $\mathrm{SiO}_{2}$ from the opening (wing) at the same time in order to minimize run-to-run or place-to-place fluctualtion. Figure 12 shows PL and PLE spectra at $10 \mathrm{~K}$ of InGaN SQW and MQW structures grown on the window and wing. As shown, they showed exactly the same properties. The luminescence decay time measured by the time-resolved PL measurements was 6 ns at RT for the MQW structure, and was independent of TD density. ${ }^{59}$ The low temperature PL lifetime was also independent of the TD density. In addition, the energy resolved of nearly TD-free InGaN MQW increased with decreasing the photon energy, as shown in Fig. 13. This is characteristics of the localized electronic system. The relation between and $E$ was fitted using $(E)={ }_{r} /\left\{1+\exp \left[\left(E-E_{m e}\right) / E_{0}\right]\right.$, where $E_{0}=60 \mathrm{meV}$ represents the depth in the tail states, $\mathrm{E}_{\mathrm{me}}=2.88 \mathrm{eV}$ is the energy similar to the mobility edge, and $\mathrm{r}=12 \mathrm{~ns}$ is the radiative lifetime. These values are reasonable for the device-quality $\mathrm{InGaN} \mathrm{QW}^{1}$ systems with highly lattice mismatched nonrandom alloy broadening.

It should be noted that all the optical properties do not depend on TD density. Conversely, the inplane net Stokes shift is affected by changing the barrier growth rate ${ }^{60}$ and InN molar fraction of the QWs. ${ }^{25}$ Therefore the in-plane effective bandgap inhomogeneity is caused by growth parameters, point defects, or thermodynamics rather than phase separation initiated by TDs. Anomalous temperature independence of the luminescence peak energy ${ }^{1,25}$ cannot be explained only by an inhomogeneous $F_{P Z}$. Since the change in $\mathrm{x}$ changes $\mathrm{F}_{\mathrm{PZ}}$, the Q-disk size / segmented QW potential may, at least partly come from the nonrandom alloy potential fluctuation emphasized by the large bowing parameter in InGaN. ${ }^{2,29,61}$

For LDs, the effective bandgap inhomogeneity more than $50 \mathrm{meV}$ is too large to obtain an uniform EHP in the well. Indeed, some InGaN MQW LDs showed EHP lasing in tail states. ${ }^{25,26,32-34,62}$ This may cause the increase of threshold current density of InGaN LDs in terms of reduiction in differential gain. ${ }^{62}$

\section{Summary}


Importance of QW exciton localization into the energy tail states was explained in addition to highfield effects in InGaN QWs. This Q-disk size potential minima make the diffusion length short and effectively keep carriers away from nonradiative pathways, which is a distinct difference between GaN and InGaN QWs. Strong F $F_{\mathrm{PZ}}$ separate e-h pair into triangular potential wells formed at opposite sides of the well and apparent Stokes-like shift is dominated by $\mathrm{F}_{\mathrm{PZ}}$ for CASE II, III, and IV. The oscillator strength of the separate e-h pair is very small for CASE III and IV. State-of-the-art InGaN LEDs and LDs generally have QWs with $\mathrm{L}=2.5-3.5 \mathrm{~nm}$ and most of blue, green, and amber LEDs may belong to pronounced CASE II. However, the overlap of e-h wavefunctions is recovered by screening $\mathrm{F}_{\mathrm{PZ}}$ by injecting carriers or doping $\mathrm{Si}$, resulting in huge blueshift of the emission peak and a decrease of the apparent Stokes-like shift. Note that vertical e-h pair distance is still smaller than $\mathrm{a}_{\mathrm{B}}$, resulting in large overlap of their wavefunctions. Therefore the localized QW excitons have strong Coulomb interaction provided that $\mathrm{L}<\mathrm{a}_{\mathrm{B}}$. In order to understand precise mechanisms of the bandgap inhomogeneity and carrier localization, and to obtain long wavelength LDs expanding from pure green to red wavelengths, fabrication and investigation of cubic zincblende InGaN QWs are mandatory to eliminate the modulation due to strain-induced piezoelectricity.

\section{Acknowledgments}

The authors are grateful to Professors U. Mishra, L. Coldren, J. Bowers, E. Hu, J. Speck, and K. Suzuki, and Drs. S. Keller, S. Fleischer, D. Cohen, J. Ibbetson, C. Bulutay, T. Azuhata, and T. Uenoyama for helpful discussions. The authors would like to thank A. Abare, M. Mack, M. Minsky, T. Deguchi, A. Shikanai, K. Torii, P. Kozodoy, M. Hansen, P. Fini, and H. Marchand for help in the experiments. The first author is thankful to Professor H. Nakanishi and Professor Y. Horikoshi for continuous encouragement.

\section{$\underline{\text { References }}$}

${ }^{1}$ S. Nakamura and G. Fasol, The Blue Laser Diode, (Springer, Berlin, 1997).

${ }^{2}$ for a review, I. Akasaki, and H. Amano, Jpn. J. Appl. Phys. 36, 5393 (1997).

${ }^{3}$ I. Akasaki, S. Sota, H. Sakai, T. Tanaka, M. Koike, and H. Amano, Electron. Lett. 32, 1105 (1996).

${ }^{4}$ K. Itaya, M. Onomura, J. Nishio, L. Sugiura, S. Saito, M. Suzuki, J. Rennie, S. Nunoue, M. Yamamoto, H. Fujimoto, Y. Kokubun, Y. Ohba, G. Hatakoshi, and M. Ishikawa, Jpn. J. Appl. Phys. 35, L1315 (1996).

${ }^{5}$ G. Bulman, K. Doverspike, S. Sheppard, T. Weeks, H. Kong, H. Dieringer, J. Edmond, J. Brown, J. Swindell, and J. Schetzina, Electron. Lett. 33, 1556 (1997).

${ }^{6}$ A. Kuramata, K. Domen, R. Soejima, K. Horino, S. Kubota, and T. Tanahashi, Jpn. J. Appl. Phys. 36, L1130 (1997).

${ }^{7}$ M. Mack, A. Abare, M. Aizcorbe, P. Kozodoy, S. Keller, U. Mishra, L. Coldren, and S. DenBaars, MRS Internet J. Nitride Semicond. Res. 2, 41 (1997); J. Cryst. Growth 180/190, 837 (1998).

${ }^{8}$ F. Nakamura, T. Kobayashi, T. Asatsuma, K. Funato, K. Yanashima, S. Hashimoto, K. Naganuma, S. Tomioka, T. Miyajima, E. Morita, H. Kawai, and M. Ikeda, J. Cryst. Growth 180/190, 841 (1998).

${ }^{9}$ M. Kneissl, D. P. Bour, N. M. Johnson, L. T. Romano, B. S. Krusor, R. Donaldson, J. Walker, and C. Dunnrowicz, Appl. Phys. Lett. 72, 1539 (1998).

${ }^{10}$ Yamada, Y. Kaneko, S. Watanabe, Y. Yamaoka, T. Hidaka, S. Nakagawa, E. Marenger, T. Takeuchi, S. Yamaguchi, H. Amano, and I. Akasaki, Proc. 10th IEEE Lasers and Electro-Optics Society Annual Meeting, San Francisco, USA, Nov. 10-13, 1997, PD1.2.

${ }^{11}$ application of LEO technique is introduced in several publications. For example, E. Bauser, Thin film growth techniques for low dimensional structures, eds. R. Farrow, S. Parkin, P. Dobson, J. Neave and A. Arrott (Plenum, New York, 1987), p. 171.

${ }^{12}$ A. Usui, H. Sunakawa, A. Sakai, and A. Yamaguchi, Jpn. J. Appl. Phys. 36, L899 (1997); A. Sakai, H. Sunakawa, and A. Usui, Appl. Phys. Lett. 71, 2259 (1997). 
${ }^{13}$ T. Zheleva, O-H. Nam, M. Bremser, and R. Davis, Appl. Phys. Lett. 71, 2472 (1997); O-H. Nam, M. Bremser, T. Zheleva, and R. Davis, Appl. Phys. Lett. 71, 2638 (1997).

${ }^{14}$ S. Nakamura, M. Senoh, S. Nagahama, N. Iwasa, T. Yamada, T. Matsushita, H. Kiyoku, Y. Sugimoto, T. Kozaki, H. Umemoto, M. Sano, and K. Chocho, Jpn. J. Appl. Phys. 36, L1568 (1997); Appl. Phys. Lett. 72, 211(1998).

${ }^{15}$ S. Nakamura, M. Senoh, S. Nagahama, N. Iwasa, T. Yamada, T. Matsushita, H. Kiyoku, Y. Sugimoto, T. Kozaki, H. Umemoto, M. Sano, and K. Chocho, Jpn. J. Appl. Phys. 37, L309 (1998).

${ }^{16}$ H. Marchand, J. Ibbetson, P. Fini, P. Kozodoy, S. Keller, S. DenBaars, J. Speck, and U. Mishra, MRS Internet J. Nitride Semicond. Res. 3, 3 (1998); H. Marchand, X. H. Wu, J. Ibbetson, P. Fini, P. Kozodoy, S. Keller, J. Speck, S. DenBaars, and U. Mishra, Appl. Phys. Lett. 73, 747 (1998).

${ }^{17}$ T. Mukai, D. Morita, and S. Nakamura, J. Cryst. Growth 189/190, 778 (1998).

${ }^{18}$ T. Mukai, H. Narimatsu, and S. Nakamura, Jpn. J. Appl. Phys. 37, L479 (1998).

${ }^{19}$ F. Ponce and D. Bour, Nature 386, 351 (1997).

${ }^{20}$ M. Suzuki, T. Uenoyama, and A. Yanase, Phys. Rev. B 52, 8132 (1995).

${ }^{21}$ F. Bernardini, V. Fiorentini, and D. Vanderbilt, Phys. Rev. B 56, R10024 (1997).

${ }^{22}$ polarity problem has been reviewed in E. Hellman, MRS Internet J. Nitride Semicond. Res. 3,11 (1998).

${ }^{23}$ A. Koukitsu, N. Takahashi, T. Taki, and H. Seki, Jpn. J. Appl. Phys. 35, L673 (1996); I-hsiu Ho and G. B. Stringfellow, Appl. Phys. Lett. 69, 2701 (1996).

${ }^{24}$ Osamura, S. Naka, and Y. Murakami, J. Appl. Phys. 46, 3432 (1975); R. Singh, D. Doppalapudi, T. D. Moustakas, and L. Romano, Appl. Phys. Lett. 70, 1089 (1997).

${ }^{25}$ properties of localized excitons in InGaN QWs are summarized in previous papers [S. Chichibu, T. Sota, K. Wada, and S. Nakamura, J. Vac. Sci. Technol. B 16, 2204 (1998) and S. Chichibu, A. Abare, M. Mack, M. Minsky, T. Deguchi, D. Cohen, P. Kozodoy, S. Fleischer, S. Keller, J. Speck, J. Bowers, E. Hu, U. Mishra, L. Coldren, S. DenBaars, K. Wada, T. Sota, and S. Nakamura, European Mater. Res. Soc. 98 Spring Meeting, Session L-IV.1, Strasbourg, France, June 16-19 (1998); Mater. Sci. Eng. B (1998; unpublished)]; original papers are S. Chichibu, T. Azuhata, T. Sota, and S. Nakamura, Appl. Phys. Lett. 69, 4188 (1996); 70, 2822 (1997); 73, 2006 (1998).

${ }^{26}$ E. Jeon, V. Kozlov, Y. Song, A. Vertikov, M. Kuball, A. Nurmikko, H. Liu, C. Chen, R. Kern, C. Kuo, and M. Crawford, Appl. Phys. Lett. 69, 4194 (1996); A. Vertikov, A. Nurmikko, K. Doverspike, G. Bulman, and J. Edmond, ibid 73, 493 (1998).

${ }^{27}$ Y. Narukawa, Y. Kawakami, Sz. Fujita, Sg. Fujita, and S. Nakamura, Phys. Rev. B 55, R1938 (1997); Y. Narukawa, Y. Kawakami, M. Funato, Sz. Fujita, Sg. Fujita, and S. Nakamura, Appl. Phys. Lett. 70, 981 (1997).

${ }^{28}$ D. A. Miller, D. S. Chemla, T. C. Damen, A. C. Gossard, W. Wiegmann, T. H. Wood, and C. A. Burrus, Phys. Rev. Lett. 53, 2173 (1984); Phys. Rev. B 32, 1043 (1985).

${ }^{29}$ T. Takeuchi, H. Takeuchi, S. Sota, H. Sakai, H. Amano, and I. Akasaki, Jpn. J. Appl. Phys. 36, L177 (1997); T. Takeuchi, S. Sota, M. Katsuragawa, M. Komori, H. Takeuchi, H. Amano, and I. Akasaki, Jpn. J. Appl. Phys. 36, L382 (1997); C. Wetzel, H. Amano, I. Akasaki, T. Suski, J. Ager, E. Weber, E. Haller, and B. K. Meyer, Mater. Res. Soc. Symp. Proc. 482, 489 (1998).

${ }^{30}$ J. Bergman, N. Saksulv, J. Dalfors, P. Holtz, B. Monemar, H. Amano, and I. Akasaki, Mater. Res. Soc. Symp. Proc. 482, 631 (1998).

${ }^{31}$ J. Im, H. Kollmer, J. Off, A. Sohmer, F. Scholz, and A. Hangleiter, Phys. Rev. B 57, R9435 (1998).

${ }^{32}$ T. Deguchi, T. Azuhata, T. Sota, S. Chichibu, and S. Nakamura, Mater. Sci. Eng. B 50, 251 (1997); T. Deguchi, A. Shikanai, K. Torii, T. Sota, S. Chichibu, and S. Nakamura, Appl. Phys. Lett. 72, 3329(1998).

${ }^{33}$ G. Mohs, T. Aoki, M. Nagai, R. Shimano, M. K-Gonokami, and S. Nakamura, Solid State Commun. 104, 643 (1997).

${ }^{34}$ S. Chichibu, D. Cohen, M. Mack, A. Abare, P. Kozodoy, M. Minsky, S. Fleischer, S. Keller, J. Bowers, U. 
Mishra, L. Coldren, D. Clarke, and S. DenBaars, Appl. Phys. Lett. 73, 496 (1998).

${ }^{35}$ H. Haug and S. Koch, Quantum Theory of the Optical and Electronic Properties of Semiconductors, (World Scientific, Singapore, 1990); W. Chow, S. W. Koch, and M. Sargent III, Semiconductor-Laser Physics, (Springer, Berlin, 1994); W. Chow, A. Wright, and J. Nelson, Appl. Phys. Lett. 68, 296 (1996).

${ }^{36}$ G. Frankowsky, F. Steuber, V. Härle, F. Scholz, and A. Hangleiter, Appl. Phys. Lett. 68, 3746 (1996).

${ }^{37}$ D. Wiesmann, I. Brener, L. Pfeiffer, M. Kahn, and C. Sun, Appl. Phys. Lett. 69, 3384 (1996).

${ }^{38}$ M. Kuball, E. Jeon, Y. Song, A. Nurmikko, P. Kozodoy, A. Abare, S. Keller, L. Coldren, U. Mishra, S. DenBaars, and D. Steigerwald, Appl. Phys. Lett. 70, 2580 (1997).

${ }^{39}$ S. Chichibu, T. Azuhata, T. Sota, and S. Nakamura, J. Appl. Phys. 79, 2784 (1996); Proc. Int. Symp. On Blue Laser and Light Emitting Diodes (Ohmsha, Tokyo, 1996), pp.202; S. Chichibu, H. Okumura, S. Nakamura, G. Feuillet, T. Azuhata, T. Sota, and S. Yoshida, Jpn. J. Appl. Phys. 36, 1976 (1997).

${ }^{40}$ B. Monemar, J. P. Bergman, H. Amano, I. Akasaki, T. Detchprohm, K. Hiramatsu, and N. Sawaki, Proc. Int. Symp. on Blue Laser and Light Emitting Diodes (Ohmsha, Tokyo, 1996), pp. 135.

${ }^{41}$ R. Dingle, D. D. Sell, S. E. Stokowski, and M. Ilegems, Phys. Rev. B 4, 1211 (1971).

${ }^{42}$ B. Monemar, Phys. Rev. B 10, 676 (1974).

${ }^{43}$ S. Chichibu, A. Shikanai, T. Azuhata, T. Sota, A. Kuramata, K. Horino, and S. Nakamura, Appl. Phys. Lett. 68, 3766 (1996); A. Shikanai, T. Azuhata, T. Sota, S. Chichibu, A. Kuramata, K. Horino, and S. Nakamura, J. Appl. Phys. 81, 417 (1997).

${ }^{44}$ G. Bastard, E. E. Mendez, L. L. Chang, and L. Esaki, Phys. Rev. B 26 (1982) 1974.

${ }^{45}$ D. A. B. Miller, D. S. Chemla, and S. Schmitt-Rink, Phys. Rev. B 33 (1986) 6976.

${ }^{46} \mathrm{E}_{\mathrm{b}}$ in $\mathrm{GaN} / \mathrm{Al}_{0.1} \mathrm{Ga}_{0.9} \mathrm{~N} \mathrm{QW}$ was calculated according to Ref. 44 using a variational method. We further consider the finite well potential. An usual variational function with two variational parameters was used as an envelop function of exciton, i.e. $\exp \left\{-\left[\mathrm{r}^{2} / \mathrm{a}^{2}+\left(\mathrm{z}_{\mathrm{e}}-\mathrm{Z}_{\mathrm{h}}\right)^{2} / \mathrm{b}^{2}\right]\right\}$, where $\mathrm{a}$ and $\mathrm{b}$ are the variational parameters, $r$ is the absolute value of the relative position of electron and hole in the $\mathrm{QW}$ plane, and $\mathrm{z}_{\mathrm{e}}\left(\mathrm{z}_{\mathrm{h}}\right)$ is the transformed $\mathrm{z}$ coordinate of the electron (hole).

${ }^{47}$ C. G. Van de Walle and J. Neugebauer, Appl. Phys. Lett. 70, 2577 (1997).

${ }^{48}$ T. Taguchi, presented at the 43rd Spring Meeting of the Japan Society of Applied Physics and Related Societies, Asaka, Japan, Mar.29, 1996 (unpublished).

${ }^{49}$ T. Mukai, M. Yamada, and S. Nakamura, Jpn. J. Appl. Phys. 37, L1358 (1998).

${ }^{50}$ C. Bulutay, N. Dagli, and A. Imamoðlu, IEEE J. of Quantum Electron. QE (1999) (unpublished).

${ }^{51}$ S. Chichibu, K. Wada, and S. Nakamura, Appl. Phys. Lett. 71, 2346 (1997).

${ }^{52}$ M. Sugawara, Phys. Rev. B 51, 10743 (1995).

${ }^{53}$ S. Rosner, E. Carr, M. Ludwise, G. Girolami, and H. Erikson, Appl. Phys. Lett. 70, 420 (1997).

${ }^{54}$ J. Speck, H. Marchand, P. Kozodoy, P. Fini, X. Wu, J. Ibbetson, S. Keller, S. DenBaars, U. Mishra, and S. Rosner, Proc. 2nd Int. Symp. on Blue Laser and Light Emitting Diodes (Ohmsha, Tokyo, 1998), pp. 37.

${ }^{55}$ H. Sato, T. Sugahara, Y. Naoi, and S. Sakai, Jpn. J. Appl. Phys. 37, 2013 (1998).

56 their results are summarized in C. Kisielowski, Proc. 2nd Int. Symp. on Blue Laser and Light Emitting Diodes (Ohmsha, Tokyo, 1998), pp. 321

${ }^{57}$ F. Ponce, S. Galloway, W. Goetz, and R. Kern, Mater. Res. Soc. Symp. Proc. 482, 625 (1998).

${ }^{58}$ S. Keller, B. Keller, M. Minsky, J. Bowers, U. Mishra, S, DenBaars, and W. Seifert, J. Cryst. Growth 189/190, 29 (1998).

${ }^{59}$ S. Chichibu, H. Marchand, S. Keller, P. Fini, J. Ibbetson, M. Minsky, S. Fleischer, J. Speck, J. Bowers, E. Hu, U. Mishra, S. DenBaars, T. Deguchi, T. Sota, and S. Nakamura, Proc. 2nd Int. Symp. on Blue Laser and Light Emitting Diodes (Ohmsha, Tokyo, 1998), pp. 604; Appl. Phys. Lett. 74,(1999) (unpublished).

${ }^{60}$ S. Keller, S. Chichibu, M. Minsky, E. Hu, U. Mishra, and S. DenBaars, J. Crystal Growth (1998) (unpublished).

${ }^{61}$ M. Mcluskey, C. Van de Walle, C. Master, L. Romano, and N. Johnson, Appl. Phys. Lett. 72, 2725 (1998). 
${ }^{62}$ K. Domen, A. Kuramata, and T. Tanahashi, Appl. Phys. Lett. 72, 1359 (1998). 